destructive process, leading to irreversible myxoedema, might have occurred in our patients.

${ }^{1}$ Kjellmann, B F, Karlberg, B E, and Kågedal, B, Nordisk Psykiatrisk Tidsskrift, 1976, 30, 528 .

2 McLarty, D G, et al, British Medical fournal, 1975, 3, 623.

3 Brownlie, B E W, et al, Australian and New Zealand fournal of Medicine, 1976, 6, 223.

${ }^{4}$ Hestbeck, J, et al, Kidney International, 1977, 3, 205.

(Accepted 21 February 1978)

Department of Internal Medicine and Endocrinology, Herlev Hospital, 2730 Herlev, Denmark

H PERRILD, MD, scientific assistant

$S$ NISTRUP MADSEN, MD, senior registrar

J E MØLHOLM HANSEN, MD, consultant physician

\section{Complete heart block due to chronic chloroquine toxicity managed with permanent pacemaker}

Chloroquine compounds are widely used as antimalarial and antiinflammatory agents. The recommended dose for malaria prophylaxis is $300 \mathrm{mg}$ of chloroquine phosphate a week. ${ }^{1}$ Although up to $900 \mathrm{mg}$ daily has been used to treat rheumatoid arthritis and systemic lupus erythematosus, the recommended maintenance dose is $250 \mathrm{mg}$ daily. ${ }^{2}$ Numerous toxic effects are associated with prolonged high dosage, ${ }^{1}$ including cerebral (mainly headache), dermatological, myopathic, neuropathic, and psychiatric disorders and, most commonly, corneal deposition and retinal degeneration. ${ }^{3}$ All these, including keratopathy and "premaculopathy," are reversible when the drug is stopped. Severe macular degeneration is rarely reversible, however, and may develop after the end of treatment. ${ }^{3}$ The development of maculopathy depends on the dosage and duration of treatment. It usually occurs with doses above $300 \mathrm{mg}$ daily and rarely before one year, although occasional idiosyncratic complications occur.

Reports of acute cardiotoxic effects are frequent and usually secondary to intentional overdosage. ${ }^{4}$ Acute idiosyncratic cardiotoxicity occurs even less commonly with chloroquine than with the related compound quinidine and is rarely ascribed to chronic chloroquine intoxication.

\section{Case report}

A 30-year-old Liberian businessman presented after four Stokes-Adams attacks in 12 hours. On admission to a local hospital he was in complete heart block with a ventricular rate of $15 / \mathrm{min}$ (fig 1 ). During the insertion of a temporary transvenous pacemaker he became asystolic with a period of ventricular tachycardia, but sinus rhythm returned after a DC shock. Electrocardiography showed right bundle-branch block and left axis deviation (fig 1). The conduction disturbance remained on transfer to this hospital two days later. There was no cardiomegaly, cardiac murmur, heart failure, or neurological, dermatological, or muscular abnormality. There was no history of angina, dyspnoea, or syncope. He was one of 18 siblings, and there was no family history of heart disease.

Malaria is endemic in Liberia, and the patient had taken six to eight chloroquine phosphate tablets (Avloclor, $155 \mathrm{mg}$ chloroquine base) a week for about three years. Whenever he developed a headache he would take extra tablets, believing it to be a sign of cerebral malaria. He took no other drugs and smoked and drank only occasionally. Over the past five months he had experienced progressive loss of vision but continued to take chloroquine. He had severe bilateral scotomata with loss of central vision, so that he could vaguely recognise objects only at the peripheries of his fields. Ocular findings were diagnostic of chloroquine toxicity, with bilateral subepithelial corneal deposits and maculopathy (fig 2). Liver and spleen were not palpable. Haemoglobin, blood film, haemoglobin electrophoresis, and a sickle-cell test were normal. No malaria parasites were found, and liver function and cardiac enzymes were normal. An echocardiogram was normal and showed no evidence of cardiomyopathy.

Three days after transfer the conduction defect remained and the patient was intermittently dependent on the pacemaker. His-bundle electrocardiography disclosed normal PA and AH conduction intervals but an $\mathrm{HV}$ interval of $65 \mathrm{~ms}$ (normal less than $55 \mathrm{~ms}$ ) and an atrioventricular Wenckebach point of $140 / \mathrm{min}$. A permanent lithium ventricular inhibited demand (a)

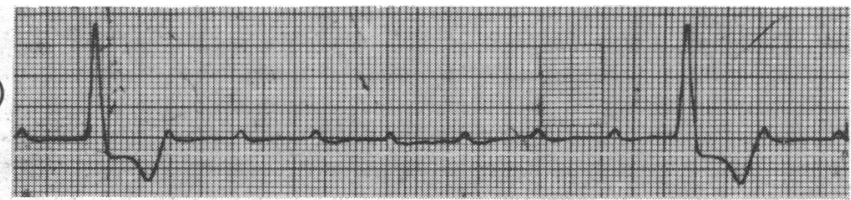
I

(b)

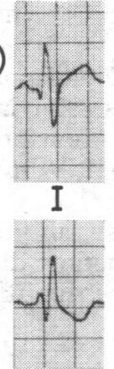

V1

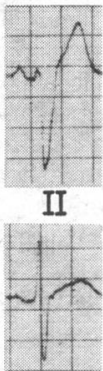

V2

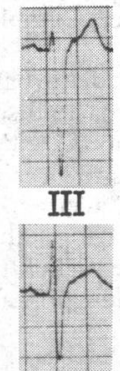

V3

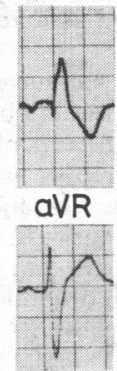

VL

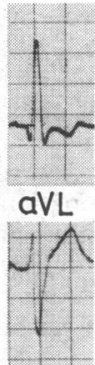

V5

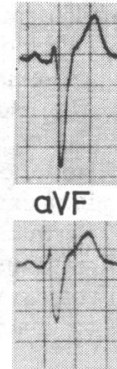

V6
FIG 1-Electrocardiograms (a) on admission, showing complete heart block; and $(b)$ after insertion of temporary pacemaker, showing sinus rhythm, right bundle-branch block, and left axis deviation.

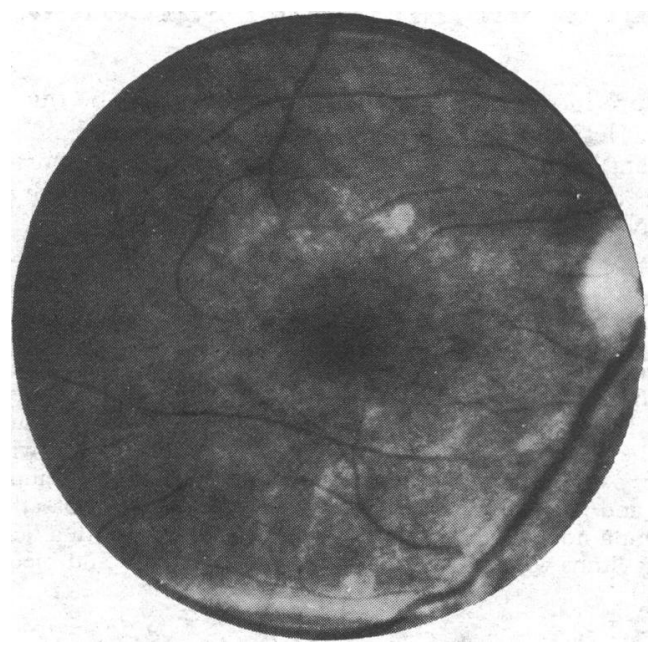

FIG 2-Ophthalmoscopic evidence of chloroquine retinopathy. Picture shows hyperpigmentation of macula and accumulation of chloroquine in melanin-containing cells (macular "bull's-eye"), paler central fovea, and surrounding retinal degeneration and oedema.

pacemaker (Telectronics 120B) was inserted with a transvenous right ventricular unipolar endocardial electrode. The threshold of stimulation was $0.3 \mathrm{~V}$. The patient returned to Liberia and was advised not to take chloroquine or related compounds again.

\section{Comment}

The therapeutic benefit of chloroquine depends on its interaction with DNA, especially in the mitochondria. In common with other class 1 antiarrhythmic compounds it has quinidine-like effects, being negatively inotropic and chronotropic, and thus causes decreased conduction in excitable cardiac tissues. It is also a prostaglandin antagonist and has been used experimentally for closing a patent ductus arteriosus. ${ }^{5}$ In acute cardiotoxicity ${ }^{6} 7$ death is secondary to the negative inotropism and chronotropism, with prolongation of HisPurkinje conduction and suppression of sinus node function leading to idioventricular rhythm, ventricular tachycardia, or fibrillation. 
Cardiac pacing has not been found beneficial, although adrenaline has a temporary effect. ${ }^{7}$ Chronic cardiac effects have rarely been described, although Hughes $e t a l^{8}$ reported two cases in which cardiac muscle was clinically affected. In one a cardiac vacuolar myopathy similar to that of the more commonly affected skeletal musculature was confirmed histologically at necropsy. Affected cardiac muscle has been found more often in experimental work on animals. The electrocardiographic changes usually found in cases of chronic intoxication are the non-specific changes in ST and T waves of generalised myocardial damage. Complete heart block has not been reported.

Pre-existing cardiac conduction disturbance is a contraindication to the use of chloroquine in rheumatic disorders. Patients receiving high-dose chloroquine treatment should undergo baseline and further, periodic electrocardiographic assessment as frequently as ophthalmological examination - that is, about every six months.

Permanent pacing was instituted in this case because of lifethreatening dysrhythmias and the belief that the conduction disturbance was due to chloroquine and probably irreversible; that this is so has not yet been proved.

We thank Mr R Daniel, consultant ophthalmic surgeon, for giving us his opinion on the retinal lesions, and $\mathrm{Dr} J \mathrm{~L}$ Thirkettle, consultant physician at Crawley Hospital, Sussex, for referring the patient.

${ }^{1}$ Martindale, W, Extra Pharmacopoeia, ed Ainley Wade, 27th edn, p 344. London, Pharmaceutical Press, 1977.

${ }^{2}$ Rodnan, G P, McEwen, C, and Wallace, S, fournal of the American Medical Association, 1973, 224, 662.

3 Scherbel, A, et al, New England fournal of Medicine, 1965, 273, 360.

4 Kiel, F W, Fournal of the American Medical Association, 1964, 190, 398.

5 Manku, M S, and Horrobin, D F, Lancet, 1976, 2, 1115.

${ }^{6}$ Charles, D, et al, Bulletin de la Société Médicale d'Afrique Noire de Langue Française, 1975, 20, 7.

${ }^{7}$ Michael, T A D, and Aiwazzadeh, S, American Heart fournal, 1970, 79, 831 .

${ }^{8}$ Hughes, J T, et al, Quarterly fournal of Medicine, 1971, 40, 85.

(Accepted 16 February 1978)

Guy's Hospital, London SE1 9RT

A C EDWARDS, MB, FRACP, cardiology research registrar

T J MEREDITH, MA, MRCP, senior house officer

E SOWTON, MD, FRCP, consultant cardiologist

\section{SHORT REPORTS}

\section{Renal failure due to glomerulonephritis in sarcoidosis}

Renal failure in sarcoidosis is uncommon and may be due to hypercalcaemia, ${ }^{1}$ lesions of the kidney itself (the typical non-caseating granulomata), ${ }^{2}$ or, rarely, glomerulonephritis. ${ }^{3}$ We report a case of sarcoidosis in which severe renal failure was associated with mesangioproliferative glomerulonephritis.

\section{Case report}

A 43-year-old married woman had been well until 1959, when she presented with weight loss and exertional dyspnoea. Sarcoidosis was diagnosed after open lung biopsy and her symptoms improved with a course of oral steroids. She remained well until June 1977, when she returned with a sevenweek history of lassitude, anorexia, weight loss, and joint pains. She was emaciated and pale with a uraemic coloration and acidotic breathing. A few axillary lymph nodes were palpable, and atrophic scars with a faint macular rash on the limbs were present. Her pulse was $100 / \mathrm{min}$ and blood pressure

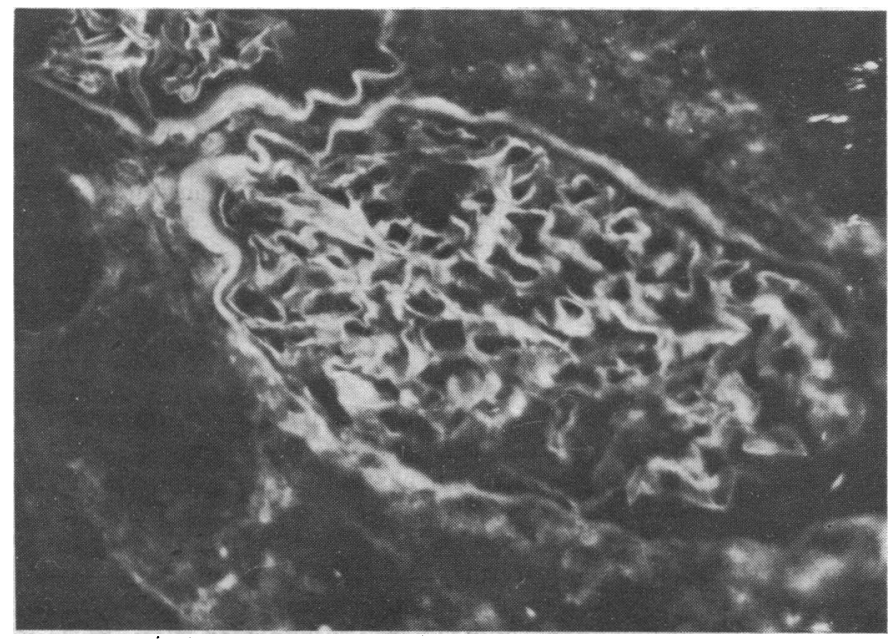

Fluorescent IgG showing granular deposits largely confined to the mesangial regions and linear staining of the capillary basement membranes $(\times 300)$.
$140 / 80 \mathrm{~mm} \mathrm{Hg}$, with a soft, apical, midsystolic murmur. She had moderate enlargement of the liver and spleen and a calcified ovarian cyst. The remaining findings were normal.

Investigations showed a normochromic normocytic anaemia ( $\mathrm{Hb} 7.9 \mathrm{~g} / \mathrm{dl})$; the serum concentration of urea was $38.7 \mathrm{mmol} / 1(232 \mathrm{mg} / 100 \mathrm{ml})$, potassium $5.8 \mathrm{mmol}(\mathrm{mEq}) / \mathrm{l}$, calcium $2.6 \mathrm{mmol} / 1(10.4 \mathrm{mg} / 100 \mathrm{ml})$, and albumin $3.3 \mathrm{~g} / 1(3.3 \mathrm{mg} / 100 \mathrm{ml})$. Her creatinine clearance was $3 \mathrm{ml} / \mathrm{min}$, and urinary protein excretion $0 \cdot 5-1 \mathrm{~g} / 24 \mathrm{~h}$. The results of the antistreptolysin-O titre, sheep cell agglutination test, latex test, antinuclear factor, and lupus erythematosus cell preparation were all negative. She had normal serum immunoglobulin and complement concentrations. Despite the presence of normal liver function tests, a liver biopsy showed typical sarcoid granulomata. Acid- and alcohol-fast bacilli were not isolated from sputum, urine, or liver, and the result of the Mantoux test was negative, $1 / 100$. A chest $x$-ray film showed right apical nodules. An intravenous pyelogram showed bilateral small, smooth kidneys with no nephrocalcinosis. A renal biopsy specimen showed a mesangioproliferative glomerulonephritis with diffuse, global, granular, and linear deposits of $\mathrm{C} 3, \mathrm{IgG}$, and IgA in basement membranes and mesangia on immunofluorescence (see figure). No calcification and no sarcoid granulomata were seen.

Initial peritoneal dialysis appreciably improved her condition. Nevertheless, her condition did not stabilise and she was started on prednisolone, $60 \mathrm{mg}$ reducing to $15 \mathrm{mg}$ per day. Her renal function improved and six weeks later the creatinine clearance had risen to $48 \mathrm{ml} / \mathrm{min}$. Her ovarian cyst was removed and she has since remained well.

\section{Comments}

Lebacq $e t a l^{1}$ found that renal failure was most conspicuous in the $11 \%$ of patients with sarcoid and hypercalcaemia. Nevertheless, our patient's serum calcium concentration was not appreciably raised. Direct involvement of the kidney by sarcoid tissue ${ }^{2}$ seems unlikely in this instance in the absence of biopsy evidence, even given the problems of sampling. Thus the cause of the renal failure here is uncertain, although similar pathological findings have been described in sarcoidosis. ${ }^{3}$ In two of these cases, ${ }^{3}$ as in this instance, both linear and granular immunofluorescence was present.

Although the aetiology of sarcoidosis remains unknown, many of its clinical manifestations such as arthralgia, erythema nodosum, and uveitis are thought to be due to circulating immune complexes, and, using the platelet aggregation technique, Hedfors and Norberg found such complexes in six out of 26 patients. ${ }^{4}$ If, as is commonly believed, such glomerular lesions are due to trapped immune complexes, this case would provide further evidence of the importance of immune complexes in sarcoidosis. The factors responsible for these remain unknown, but may result from other immunological disturbances occurring in sarcoidosis. ${ }^{5}$

We thank Dr A M Holmes for helpful advice and permission to report a 